Revista de la red interuniversitaria de estudios sobre las literaturas rioplatenses contemporáneas en Francia

$14 \mid 2016$

Levrero

\title{
Sobre los mecanismos de la creación
}

\section{Mario Levrero}

URL: http://journals.openedition.org/lirico/2302

DOI: $10.4000 /$ lirico.2302

ISSN: 2262-8339

Editor

Réseau interuniversitaire d'étude des littératures contemporaines du Río de la Plata

Referencia electrónica

Mario Levrero, «Sobre los mecanismos de la creación », Cuadernos LIRICO [En línea], 14 | 2016, Puesto en línea el 07 junio 2016, consultado el 19 abril 2019. URL : http://journals.openedition.org/lirico/2302 ; DOI : 10.4000/lirico.2302

Este documento fue generado automáticamente el 19 abril 2019.

\section{(c) $(1) \Theta \Theta$}

Cuadernos LIRICO está distribuido bajo una Licencia Creative Commons Atribución-NoComercialSinDerivar 4.0 Internacional. 


\title{
Sobre los mecanismos de la creación
}

\author{
Mario Levrero
}

1 La propuesta del tema nos es formulada con cierta prepotencia, como incitándonos a aceptar de antemano que hay mecanismos ; mi respuesta inmediata es que si los hay, los desconozco. Sólo puedo ofrecer reflexiones que bordean el tema.

2 Supongo que debe haber alguna diferencia esencial entre la creación de automóviles en serie y, por ejemplo, ciertas formas de la literatura ; tal vez esta diferencia radique sólo en la intención, y por ese lado podría escarbarse.

3 ¿Qué significa la palabra creación? Que los lingüistas nos ayuden; yo pienso en Antonio Machado, opinando que tal vez Dios no creó otra cosa que la Nada, como un pizarrón negro con toda su posibilidad de libertad y de angustia, y que el "Diccionario Hispánico Universal" de la editorial Jackson señala que la palabra "nada" proviene del latín "res nata", "cosa nacida". Por otra parte me tienta el juego de palabras que no es tal : crear, criar, creatura, criatura. Crear es arrojar al mundo algo que antes no estaba, o también, y sobre todo, criarlo, es decir, alimentarlo, educarlo. Y dentro de esta comparación con lo biológico : 1) lo que "antes no estaba", ¿no estaba, realmente, como plan genético ? Y 2) ¿no es este "echar al mundo" un proceso "mecánico" (o más bien automático) ? Y 3) lo que "antes no estaba", pero que estaba de alguna manera, no pasa a transformarse en algo realmente nuevo o realmente real, realmente existente, a partir de ese tratamiento de la "crianza"?

Felisberto Hernández, en la explicación falsa de sus cuentos, advierte el automatismo de ese proceso interior donde el escritor es apenas una especie de jardinero que observa, riega y poda. ¿Puede hablarse de "creación" si no es estrictamente en el sentido de "crianza"? (Hablo del plano del hombre, no de Dios). Justamente en los productos más auténticos, como la obra de Felisberto, veo el resultado de un proceso diría fisiológico del espíritu, si se me permite el disparate. Un proceso espiritual de ingestión, asimilación y excreción. Es cierto que de alguna manera se selecciona lo que se ingiere, con cierta libertad o falta de libertad consciente o inconsciente, dentro de las limitaciones de lo que nos es dado e impuesto ; y está la sensibilidad (justamente, lo que distingue a un escritor auténtico de otro que no lo es, o de un no escritor, lo que hace posible apreciar la 
diferencia que existe entre la fabricación de automóviles y la literatura), que, permite advertir el proceso, observarlo sin distorsionarlo demasiado; y está la capacidad de anotarlo con mayor o menor fidelidad, sin dejar nada en el tintero, podando los brotes viciosos y arrancando los yuyos; y, aún, la capacidad de estimular conscientemente no sólo el proceso, sino incluso una cierta dirección en el proceso automático ; y la intuición para percibir cuáles son las mejores semillas (o, en la metáfora fisiológica, los mejores alimentos).

Después viene el oficio, que en sí mismo no es innoble. En cuanto jardinero, conviene conocer las herramientas y el comportamiento de las plantas: hay una técnica de la jardinería.

Pero son legión quienes aprenden la técnica, adquieren el oficio y lo manejan a voluntad. No son jardineros. No son creadores. Su voluntad no está al servicio de las plantas.

Puede parecer horrible la propuesta : el escritor auténtico (el creador en general), un ser casi ajeno a un proceso automático que casi le es dado; el escritor de oficio (oficial, oficina), ejerciendo casi libremente su voluntad. Pero los casi pueden cambiar esencialmente el sentido de las cosas.

8 Es la presencia del Espíritu, con perdón de la palabra, lo que diferencia dos hechos aparentemente similares (dos textos con igual calidad de oficio). Hay quienes inventan, es decir, descubren, aunque inventen la pólvora en la era atómica; hay quienes aprenden una técnica y la usan, pero no pueden inventar ; el Espíritu no puede copiarse.

En un Universo que mantiene planteadas todas las preguntas primordiales del hombre, donde el Ministerio, digan que no, sigue imponiéndose como el primer día, es difícil (amén de desmedidamente pretencioso) no ser un instrumento. El creador, como jardinero al servicio del jardín, como instrumento de un proceso automático, me parece un bello instrumento. Otros instrumentos, muy bien afinados, útiles, voluntariosos, pueden estar al servicio de otros intereses y, en última instancia, ser definitivamente vanos. Es una cuestión de autenticidad. Y de intención, como decía antes. Descubro ahora que me interesan más las intenciones que los mecanismos.

Maldoror, $\mathrm{N}^{\circ}$ 9, noviembre 1973 